\title{
TINGKAT DAYA TAHAN AEROBIK (VO2MAX) SISWA EKSTRAKURIKULER GULAT DI SMA NEGERI 1 BARUSJAHE KABUPATEN KARO
}

\author{
Jan Bobby Nesra Barus \\ Universitas Quality Berastagi, email :bobbybarusbb@gmail.com
}

\begin{abstract}
Abstrak
Daya tahan aerobik yang berkaitan dengan sistem kardioraspiratori dapat dilihat hasilnya dengan melihat VO2Max atau kapasitas oksigen maksimal yaitu kemampuan seseorang dalam konsumsi oksigen secara maksimal dalam melakukan aktivitas kerja fisik.Tujuan penelitian ini adalah untuk mengetahui tingkat tingkat VO2Max siswa ekstrakurikuler gulat di SMA Negeri 1 Barusjahe Tahun 2020. Jenis penelitian ini adalah survei,Teknik penarikan sampel menggunakan purposive sampling. Teknik pengumpulan data menggunakan observasi wawancara, dan tes pengukuran Daya tahan kardiorespiratori dengan menggunakan tes dari Kenett $\mathrm{H}$ Coppert yaitu Cooper Test $2.4 \mathrm{~km}$ khusus untuk usia dibawah 30 tahun. Populasi penelitian yaitu seluruh siswa ekstrakulikuler gulat di SMA Negeri 1 Barusjahe.Teknik pengumpulan data yang digunakan pada penelitian ini yaitu dengan melalui tes VO2Max. Hasil penelitian diperoleh bahwa daya tahan aerobik (Vo2 Max) siswa ekstrakulikuler gulat di SMA Negeri 1 Barusjahe Kabupaten Karo termasuk dalam kategori sedang sebanyak 9 orang siswa atau 60\%, pada kategori baik sebanyak 3 orang siswa atau $20 \%$ dan dikategori kurang sebanyak 3 orang siswa atau 20\%.Sehingga disimpulkan bahwa tingkat Vo2Maxpada siswa yang mengikuti kegiatan ekstrakulikuler gulat di SMA Negeri 1 Barusjahe Kabupaten Karo yaitu sedang.
\end{abstract}

Kata Kunci :Ekstrakulikuler, VO2Max, Olahraga, Gulat

\begin{abstract}
Aerobic endurance related to the cardior aspiratory system can be seen by looking at VO2Max or maximum oxygen capacity, which is the ability of a person to consume oxygen maximally in carrying out physical work activities. The purpose of this study was to determine the level of VO2Max level of wrestling extracurricular students in SMA Negeri 1 Barusjahe in 2020. This type of research is a survey, the sampling technique using purposive sampling. Data collection techniques using interview observation, and measurement tests cardiorespiratory endurance using tests from Kenett H Coppert namely Cooper Test $2.4 \mathrm{~km}$ specifically for ages under 30 years. The study population was all wrestling extracurricular students at SMA Negeri 1 Barusjahe. Data collection techniques used in this study is through the VO2Max test. The results showed that aerobic endurance (Vo2 Max) of wrestling extracurricular students in SMA Negeri 1 Barusjahe Karo Regency included in the moderate category of 9 students or $60 \%$, in either category 3 students or $20 \%$ and in the category of less than 3 students or 20\%. So it was concluded that the level of Vo2Max in students who take wrestling extracurricular activities in SMA Negeri 1 Barusjahe Karo District is moderate.
\end{abstract}

Keywords: Extracurricular, VO2Max, Sports, Wrestling 


\section{PENDAHULUAN}

Pendidikan dalam pembangunan suatu bangsa merupakan indikator yang sangat penting agar bangsa tersebut dapat berkembang dan maju.Melalui pendidikan diharapkan dapat menguasai berbagai teknologi informasi yang akan dipergunakan dimasa saat ini dan mendatang. Berbagai upaya yang telah dilakukan oleh pemerintah agar bidang pendidikan di Indonesia dapat berkembang dengan baik.Berbagai kebijakan yang mengarah pada pendidikan yang sesuai dengan perkembangan zaman seperti saat ini yaitu dalam menghadapi revolusi industri keloahragaan 4.0. menurut Apri (2012) bahwa olahraga dapat menciptakan manusia yang sehat. Melalui olahraga dilakukan berbagai pembinaan setiap generasi yang akan berkontribusi positif terhadap peningkatan manusia dalam menjalankan pembangunan yang berkelanjutan.

Salah satu upaya dibidang
pendidikan yang mengarah pada keolahragaan 4.0 yaitu dengan melihat kualitas sumber daya manusia yang melalui pendidikan jasmani. Pendidikan jasmani yang dimaksud adalah suatu proses dalam pendidikan yang melibatkan segala aktivitas fisik agar dapat mengalami suatu perubahan bersifat holistik pada individudapat dilihat dari kondisi jasmani atau rohani. Sehingga dapat disimpulkan bahwa pendidikan jasmani adalah pendidikan berperan sangat penting dalam kemajuan suatu bangsa melalui pelatihan olahraga.Suharjana (2013: 47) mengatakan bahwa padaumumnya pada suatu frekuensi latihan lebih lama akan menyebabkan kondisi kebugaran jasmani akan semakin baik.

Pendidikan jasmani memiliki tujuan dalam mengembangkan kebugaran jasmani, keterampilan bergerak, kemampuan berfikir kritis, memiliki pola hidup yang sehat, serta pengenalan terhadap kondisi lingkungan bersih sehingga akan tercapai tujuan dari pendidikan nasional. Disisi lain, kebugaran jasmani bertujuan untuk peningkatan prestasi belajar siswa disekolah ataupun dikegiatan luar pelajaran seperti kegiatan ekstrakulikuler. Kondisi kebugaran jasmani dapat dipengaruhi oleh beberapa faktor pendukung seperti konsumsi makanan dan kondisi tubuh yang baik. Apagila kondisi tubuh sehatmaka tingkat daya tahan aerobik akan baik pula. Tingkat VO2Maxmerupakankemampuan individu untuk menghirup dan mengeluarkan oksigen dengan maksimal.

VO2Maxdiartikan faktor penentu dari tingkat kebugaran yang berperan penting untuk atlet ataubukan atlet.Kebutuhan untuk bukan atlet sangat berfungsibagi kesejahteraan tubuh yang sehat, sedangkanuntuk seorang atlet, tingkat VO2Max adalah sesuatu yang sangat vital.Hal ini dikarenakan atlet dalam menjalankan aktivitas olahraga membutuhkan tingkat kebugaran yang tinggi.upaya yang dapat dilakukan untuk meningkatkan VO2Max yaitu melalui kegiatan latihan yang dilakukan secara rutin, agar tubuh dapat merespon dengan baik dan kinerja otot pernafasan dan paruparu dapat bekerja secara maksimal.

Latihan dapat dikatakan baik dan berguna untuk meningkatkan VO2Maxyaitu berupa diperlukan program latihan yang efektif supaya dapat menjadikan hasil yang optimal.Untuk meningkatkan VO2Max dapat melalui latihan rutin.Dalam latihan dapat dilakukan dengan latihan kesegaran aerobik.Kesegaran aerobik adalah kemampuan jantung, paru dan pembuluh darah dalam menggunakan oksigen dan memanfaatkan menjadi tenaga secara optimal untuk melakukan aktivitas dengan waktu yang tergolong lama tanpa menimbulkan efek kelelahan yang berlebihan (Hastuti, 2008). 
Ekstrakurikuler merupakan aktivitas kegiatan yang dalam pelaksanaannya dilakukan di luar jam sekolah. Kegiatan ekstrakurikuler dapat dilakukan di lingkungan sekolah atau di luar sekolah.bertujuan dari mengikuti ekstrakurikuler yaitu untuk lebih memperluas wawasan dan meningkatkan pengetahuan yang dimiliki pada bidang tertentu. Salah satu ekstrakurikuler dibidang olahraga yang diminati oleh siswa di sekolah adalah gulat.Olahraga gulat adalah bagian dari olahraga bela diri. Gulat dalam aktivitasnya banyak menggunakan berbagai gerakan-gerakan seperti kombinasi dorongan, tarik, putaran, mengangkat, membanting, kuncian dan lainnya, yang bertujuan agar lawan tidak stabil sehinggga dapat menjatuhkan lawan dalam satu set serangan.

SMA Negeri 1 Barusjahe Kabupaten Karo merupakan satu sekolah yang menyelenggarakan kegiatan ekstrakurikuler gulat.Tujuan SMA Negeri 1 Barusjahe mengadakan ekstrakurikuler yaitu untuk melatih keterampilan dan kemampuan siswa disekolah tersebut.Salah satu kegiatan ekstrakurikuler diadakan yaitu gulat.Ekstrakurikuler gulat dikalangan siswa termasuk ynag cukup digemari oleh siswa di SMA Negeri 1 Barusjahe, sebanyak 15 orang siswa yang mengikuti kegiatan ekstrakurikuler.Kegiatan ekstrakurikuler gulat dilaksanakan sekali dalam satu minggu.

Hasil pengamatan oleh peneliti diketahui bahwa kegiatan ekstrakurikuler gulat SMA Negeri 1 Barusjahe pada tahun 2019mengingat olahraga gulat adalah olahraga yang sangat kompleks dan membutuhkan dasar daya tahan aerobik yang baik. Daya aerobik merupakan fondasi dasar membangun kebugaran jasmani yang berperan sangat penting untuk setiap cabang olahraga, hal ini dikarenakan kebugaran jasmani nafas bagi para atlet dalam melakukan teknik dan taktik dalam kompetisi. Meningkatkan daya tahan aerobik seorang siswa ekstrakulikuler membutuhkan keseimbangan konsumsi makanan yang bergizi, istirahat yang cukup dan aktivitas lain yang mendukung untuk mampu dalam peningkatan daya tahan aerobik siswa.

Keadaan di SMA Negeri 1 Barusjahe tersebut dapat dijadikan sebagai bukti agar perlu dilakukan kegiatan agar kondisi fisik siswa dapat menjadi optimal sehingga pada akhirnya akan menunjang kegiatan belajar mengajar di dalam ruangan. Selain itu juga, berdasarkan pengamatan dan wawancara dengan guru disekolah tersebut, selama ini guru belum melakukan pengukuran tingkat kebugaran siswa di sekolah SMA Neger 1 Barusjahe khususnya dalam olahraga gulat.

Berdasarkan latar belakang yang telah dijabarkan maka peneliti tertarik untuk mengetahui tingkat daya tahan aerobik (Vo2Max) pada siswa yang ikut kegiatan ekstrakurikuler olahraga gulat di SMA Negeri 1 Barusjahe.Selain itu, sebelum dilaksanakan penelitian dilakukan survey diketahui bahwa belum ada yang melakukan penelitian mengenai tingkat daya tahan aerobik (Vo2Max) di sekolah tersebut terkhusus olahraga gulat.Sehingga tujuan dari penelitian ini adalah seberapa besar tingkat daya tahan aerobik (Vo2Max) siswa ekstakurikuler gular di SMA Negeri 1 Barusjahe Kabupaten Karo.

Daya tahan aerobik (VO2Max)merupakan kemampuan individudalam mengambil atau menyajikan oksigen agar dapat di maksimal.VO2Max sangat penting terutama bagi seorang manusia.Bagi atlet Vo2Max adalah faktor utama untuk menunjang prestasi yang ingin dicapai, artinya melalui kondisi daya tahan tubuh yang baik maka aktivitas latihan yang dilakukan dapat berjalan dengan baik.Sedangkan baik non atlet, Vo2Max dipergunakan untuk 
kesejahteraan kesehatan. Hal senada juga diungkapkan olehIntan Watulingas dkk (2013:1065) bahwa VO2 Max yaitu jumlah oksigen, yang dapat digunakan dalam satu menit per kilogram berat badan. Seseorang yang memiliki tingkat kebugaran yang baik akan menjalankan aktivitas yang baik pula.Sedangkan menurut Benny B. (2012:15) bahwa dalam mengambil oksigen dalam eksersi maksimum yang dinyatakan satuan liter atau menit.

Menurut Pramatasari (2012) bahwa kapasitas aerobik dapat dikatakan VO2Max dapat secara maksimal jika kemampuan dari kapasitas orang tersebut untuk dapat menggunakan oksigen semakin banyak.Indikator digunakan dalam melakukan pengukurandari kebugaran jasmani yaitu melalui tes Vo2Max.Dimana volume oksigenyang maksimal pada saat tubuh melakukan prosesaktivitas kegiatan yang dianggap sangatintensif. Jika semakin banyak kadaroksigen yang diserap atau digunakan tubuh, maka akan menunjukkan semakin baik pula kinerja otot dalam bekerja. Pada masanya, sisa dari zat yang akanmenimbulkankelelahan jumlahnya juga akan semakin berkurang. daya tahan tubuh (VO2Max) dapat diukur dari banyak jumlahoksigen dalam satuan liter/menit dan disesuaikan dengan kondisi berat badan orang tersebut.

Warni dkk (2017) menyebutkan bahwa VO2Max diistilahkan dengan tenaga aerobik maksimum atau penggunaan oksigen dengan dalam yang tempo tercepat yaitu konsumsioksigen yang cukup banyak selama menjalankan aktivitasolahraga.Sehingga dapat disimpulkan bahwa daya tahan aerobik (VO2Max) mengacu pada kemampuan kecepatan dalam pemakaian oksigen bukan sekedar oksigen banyak dipakai, akan tetapi untuk kepentingan apa. Akan tetapi dapat dikatakan jika seseorang melakukan suatu pekerjaan dalam tempo waktu lama, maka kebutuhanoksigen untuk mempertahankan daya tahan (stamina) menjadi stabil.Jadi dapat disimpulkan bahwa VO2Max disebut juga transport oksigen secara maksimum dalam tempo tercepat oleh seseorang dapat menjalanakan aktivitas yang dipergunakan untuk tujuan berolahraga.

Menurut (Yuyun\&Fitria, 2015: 2)kegiatan ekstrakurikuler bidang olahraga yaitu suatu aktivitas kegiatan latihan cabang olahraga yang diselenggarkan oleh sekolah.Kegiatan ekstrakurikuler pada sekolah dilakukan pada jam usai sekolah. Dalam penyelenggaraan ekstrakurikuler disekolah, guru bertanggungjawab dalam pelaksanaannya.Adapun guru yang diberikan tanggungjawab tergantung pada bidang ekstrakurikuler seperti bidang kesiswaan, guru penjaskes dan lainnya.Salah satu bidang olahraga ekstrakurikuler yang ada yaitu ekstrakurikuler gulat.

\section{METODE}

Lokasi pada penelitian tingkat daya tahan aerobik (Vo2Max) dilakukan di SMA Negeri 1 Barusjahe Kabupaten Karo.pemilihan lokasi penelitian berdasarkan pada sekolah SMA Negeri 1 Barusjahe adalah sekolah yang menyelenggarakan kegiatan ekstrakurikuler gulat di Kabupaten Karo.

$$
\text { Penelitian tingkat VO2Max }
$$
merupakan penelitian deskriptif.Metode pengumpulan data yaitu dengan menggunakan metode survei.Instrumen pada penelitian ini yaitu memakai tes dari Cooper Test $2.4 \mathrm{~km}$ oleh Kenett $\mathrm{H}$ Cooper.Menurut pendapat Sugiono (2010)penelitian deskriptif merupakan suatu metode yang digunakan pada penelitian dengan objek yang diamati berupa kelompok manusia.Penelitian deskriptif bertujuan mendeksripsikan suatu keadaan yang dibuat dalam bentuk gambaran secara fakta. 
Variabel penelitian ini terdiri dari daya tahan aerobik (Vo2Max) pada siswa SMA Negeri 1 Barusjahe Kabupaten Karo.Menurut Sugiyono (2010: 297) bahwa populasi adalahobyek maupun subyek yangakan diteliti. Objek/subjek tersebutdipilih berdasarkan padakriteria yang telah ditetapkan oleh peneliti untuk dijadikan sebagai permasalahan dalam penelitian dan ditemukan jawaban.Pada penelitian ini populasi yaitu seluruh siswadi SMA Negeri 1 Barusjahe Kabupaten Karo yang mengambil ekstrakurikuler gular dengan jumlah sebanyak 15orang siswa. Seluruh populasi yang ada dipergunakan oleh peneliti sebagai subjek yang akan diamati.

Data dikumpulkan melalui tes mengukur tingkat VO2Max pada siswa ekstrakurikuler gular.Tes yang dilakukan yaitu tes lari multy stage running test. Kegiatan awal tes dilakukan dengan beberapa tahapan diantaranya yaitu siswa melakukan tes lari secepat-cepatnya dengan jarak tempuh yaitu $2,4 \mathrm{~km}$. Tes Cooper harus memiliki lintasan yang datar dan tidak bergelombang, tidak licin dan belokan tidak terlalu tajam. Pencatatan waktu tempuh yang dilakukan oleh peserta dibuat dalam satuan menit dua angka dibelakang koma, gunanya untuk memprediksi kemampuan tingkat kebugaran peserta tes dengan membandingkan tabel tingkat kebugaran milik Cooper. Tebel 1 adalah taksiran norma penilaian tes dengan menggunakan Cooper.

Tabel 1.Kategori Penilaian Klasifikasi terhadap VO2Max

\begin{tabular}{c|l|c}
\hline No & \multicolumn{1}{|c|}{ Kategori } & Kapasitas Aerobik \\
\hline 1. & Baik Sekali & Ke atas $-54,30$ \\
\hline 2. & Baik & $54,20-49,30$ \\
\hline 3. & Sedang & $49,20-44,20$ \\
\hline 4. & Kurang & $44,10-39,20$ \\
\hline 5. & Kurang Sekali & $39,10-$ ke bawah \\
\hline
\end{tabular}

\section{HASIL DAN PEMBAHASAN}

Disrupsi olahraga pada era revolusi industry 4.0 juga merupakan kebutuhan. Olahraga berkaitan dengan cara hidup, cara pandang, berinteraksi, berkompetisi, berkomunikasi yang bermetamorfosis pada kekhasan era digitalisasi teknologi. Dalam hal ini, pendidikan olahraga dapat dipergunakan untuk mencapai tujuan melalui aktivitas jasmani yang tersusun. Menurut (Rahmad, 2016) bahwa olahraga memiliki pengaruh terhadap peningkatan kebugaran jasmani dan rohani manusia dengan hasil berkualitas yang dapat dipergunakan untuk proses pembangunan bangsa yang bugar.

Penelitian tentang tingkat daya tahan aerobik (VO2 Max) dilakukan oleh Ninzar (2018) dengan judul Tingkat Daya Tahan Aerobik (Vo2 Max) Pada Anggota Tim Futsal Siba Semarang.Penelitian ini bertujuan untuk mengetahui tingkat daya tahan (VO2Max) pada anggota tim futsal SIBA. VO2 max didefinisikan sebagai jumlah maksimum oksigen yang digunakan dalamsatuan milliliter, sehingga dapat digunakan dalam satu menit per kilogram berdasarkan berat badan seseorang. Orang dengan tingkat kebugaran baik akan memiliki tingkat nilai VO2Max lebih tinggi jika dibandingkan dengan yang rendah tingkat kebugaran. Vo2Max sangat membantu seseorang dalam melakukan segala aktifitas dengan kondisi tubuh yang lebih kuat.

Penelitian ini merupakan jenis penelitian kuantitatif non eksperimen dengan menggunakan model pendekatan deskriptif kuantitatif. Populasi dalam penelitian ini adalah tim futsal SIBA yang berjumlah 35 orang dan akan dijadikan sampel untuk anggota yang aktif dalam latihan. Oleh karena itu untuk mengetahui daya tahan pemain bias diketahui berdasarkan tingkatVO2 Max melalui tes Multistage Fitness Test (MFT). 
Penelitian selanjutnya oleh (Budi dan Sugiharto, 2015)berdasarkan hasil Penelitian yang dilakukan menunjukkan bahwa nilai rata-rata hasil pre-test yang dilakukan pada circuit training rasio $1: 1$ yaitu sebesar 42,32 dan pada post-test yaitu sebesar 47,32. Disisi lain, circuit training pada rasio $1: 2$ dengan nilai ratarata pre-test yaitu sebesar 42,29 dan nilai post-test yaitu sebesar 45,98. Sehingga dapat disimpulkan bahwa pada penelitian circuit training dapat meningkatkan volume oksigen maksimal (VO2 Max) pada atlet Puslat sepak bola Putra Ngaliyan Semarang.

Sementaramenurut Bayu (2017) pada penelitian yang dilakukannya judul Profil Tingkat Vo2 Max Pada Siswa Sekolah Sepakbola (Ssb) Palembang Muda. Berdasarkan hasil penelitian diperoleh profil tingkat VO2 Max siswa sekolah sepakbola Palembang muda pada kategori istimewa sebesar $0 \%$, pada kategori baik sekali sebesar $0 \%$, pada kategori baik sebesar $15 \%$, pada kategori sedang sebesar $40 \%$, kategori kurang sebesar 35\%, dan kategori kurang sekali sebesar $10 \%$. Hal ini dapat disimpulkan bahwa profil VO2 Max pada siswa sekolah sepakbola Palembang muda adalah sedang.

Penelitian tingkat VO2MAX siswa ekstrakulikuler gulat dilaksanakan di SMA Negeri 1 Barusjahe Kabupaten Karo, pengambilan data pada penelitian ini dilakukan pada tanggal 30-31 Januari 2020.Responden.Subjek pada penelitian ini yaitu siswa yang mengikuti ekstrakulikuler gulatdi SMA Negeri 1 Barusjahe Kabupaten Karo sebanyak 15 orang.

Daya tahan yang dimaksud pada penelitian ini diukur berdasarkan pada tes 2,4 km Cooper dengan mengikuti prosedur VO2MAX. Hasil penelitian daya tahan pada siswa yang diamati dari responden sebanyak 15 orang. Hasil penelitian tingkat daya tahan aerobik (Vo2Max) pada siswa yang mengikuti kegiatan ekstrakulikuler gulat di SMA Negeri 1 Barusjahe Kabupaten Karo dilihatmelalui tabel 2 berikut.

Tabel 2. Hasil Analisis KategoriTingkat Vo2Max pada Siswa Ekstrakulikuler Gulat di SMA Negeri 1 Barusjahe

\begin{tabular}{c|l|c|c}
\hline No & \multicolumn{1}{|c|}{ Kategori } & $\begin{array}{c}\text { Frekue } \\
\text { nsi }\end{array}$ & $\begin{array}{c}\text { Persentase } \\
\mathbf{( \% )}\end{array}$ \\
\hline 1 & Baik Sekali & 0 & 0,00 \\
\hline 2 & Baik & 3 & 20,00 \\
\hline 3 & Sedang & 9 & 60,00 \\
\hline 4 & Kurang & 3 & 20,00 \\
\hline 5 & Kurang Sekali & 0 & 0,00 \\
\hline \multicolumn{2}{r}{ Jumlah } & 15 & 100,00 \\
\hline
\end{tabular}

Jika dilihat tingkat VO2Max dalam bentuk diagram maka akan terlihat seperti pada gambar 1 berikut ini.

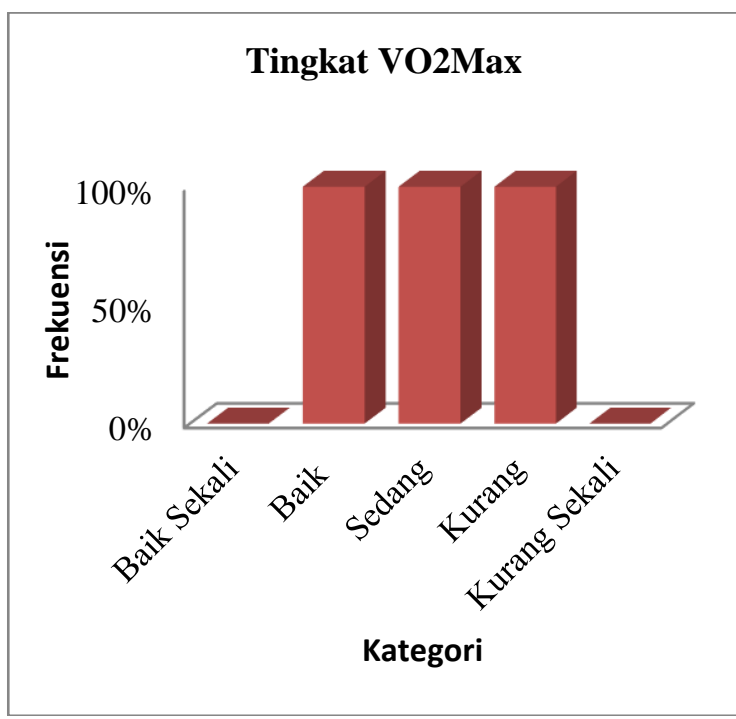

Gambar 1. Tingkat VO2Max pada siswa Ekstrakulikuler Gulat di SMA Negeri 1 Barusjahe

Berdasarkan tabel 2 dan gambar 1 bahwa tingkat VO2Max pada siswa yang mengikuti kegiatan ekstrakulikuler gulat di SMA Negeri 1 Barusjahe termasuk pada kategori sedang sebanyak 9 orang siswa atau $60 \%$, pada kategori baik sebanyak 3 orang siswa atau $20 \%$ dan dikategori kurang sebanyak 3 orang siswa atau $20 \%$. Untuk baik sekali dan kurang sekali tidak ada. 


\section{Pembahasan}

Kapasitas aerobik maksimal (Vo2 Max) merupakan kapasitas ataupun kemampuan individu dalam menggunakan oksigen sebanyak mungkin atau dapat dikatakan dengan indikator tingkat kebugaran jasmani individu.VO2Max pada seseorang bisa dipengaruhi berbagai aktivitas fisik yang dijalankan ataupun melalui pola hidup sehari-hari.Dengan hasil tersebut diartikan sebagian besar siswa mempunyai aktivitas dengan kategori sedang untuk mendukung aktifitas fisik yang akan dilakukan sehari-hari. Jika dilihat dari tabel 2 dan gambar 1, bahwa tingkat Vo2Max siswa ekstrakulikuler gulat di SMA Negeri 1 Barusjahe sebagian besar berada pada kategori sedang $60 \%$, diikuti kategori baik $20 \%$, kategori kurang $20 \%$, untukkategori baik sekali dan kategori sangat kurang tidak memiliki nilai frekuensi.Menurut (Rismayanthi, 2012)bahwa kegiatan ekstrakurikuler olahraga disekolah sangat penting bagi siswa. Hal ini dikarenakan kegiatan olahraga dapat membuat siswa menjadi sehat dan segar. Kondisi siswa yang sehat dan bugar akan mampu meningkatkan tingkat konsentrasi siswa dalam belajar, sehingga pada akhir akan berkontribusi dalam peningkatan prestasi belajar siswa disekolah.

Berdasarkan hasil pengamatan yang dilakukan oleh peneliti bahwa sebagian besar siswa yang mengikuti kegiatan ekstrakulikuler gulat di SMA Negeri 1 Barusjahe terlihat aktif dalam berlatih gulat dengan frekuensi sebanyak 3 kali dalam seminggu.Sehingga dapat disimpulkan bahwa kondisi fisik khususnya daya tahan aerobik pada siswa cenderung meningkat.Dalam hal ini, dapat dilihat berdasarkan salah satu bukti bahwa kegiatan ektrakulikuler di sekolah khususnyapada ektrakulikuler gulat dapat dilakukan peningkatan kebugaran VO2Max melaluisiswa secara lebih optimal lagi.Hal ini sejalan dengan pendapat Hanfiah (2015), semakin besar VO2Max yang dimiliki maka akan meningkatkan tingkat kebugaran jasmani yang baik pula, sebaliknya jika tingkat VO2Max tersebut rendah maka tingkat kebugaran jasmani akan rendah maupun kurang.

Prinsip pada latihan yaitu melalui suatu proses perubahan menuju kearah yang lebih baik. Artinya perlu dilakukan peningkatan kualitas fisik siswa, fungsional tubuh dan kualitas psikis individu yang diamati.Sehingga diharapkan jika semakin tinggi melakukan aktivitas fisik setiap hari, akan berdampak pada tingkat VO2Max.upaya yang dapat dilakukan untuk meningkatkan VO2Max yaitu melalui latihan

seperti melalui aktif dalam kegiatan yang berhubungan dengan olahraga yaitu ekstrakulikuler gulat.

Beberapa faktor pendukung yang dianggap memiliki pengaruh terhadap tingkat VO2Max seperti pola makan bergizi, waktu istirahat, lingkungan dan kebiasaan yang dilakukan.Siswa berada pada masa pertumbuhan dan perkembangan organ tubuh.Artinya, tugas utama yang dapat dilakukan oleh siswa yaitu dengan tetap menjaga kebugaran fisik. Sehingga akan dapat mendukung segala aktivitas siswa tersebut dalam menjalankan kegiatan disekolah dan ekstrakurikuler gulat yang diikuti. Ini berarti perlu dilakukan latihan-latihan fisik agar kebugaran VO2Max dapat tetap dipertahankan atau malah perlu dilakukan peningkatan kearah yang lebih baik lain.

Nutrisi menjadi faktor pendukung terpenting bagi yang akan mempertahankan tingkat VO2Max. kandungan nutrisi makan yang berkualitas akan mencukupi asupan didalam tubuh. Dimana, nutrisi tersebut akan dipergunakan oleh siswa dalam latihan ekstrakurikuler gular disekolahnya. Nutrisi yang baik akan mencukupi kebutuhan 
energy siswa agar kondisi tubuh tetap dalam keadaan sehat dan fit.Menurut (Darsi, 2018), terdapat beberapa pengaruh yang disebakan oleh kesegaran jasmani, diantaranya gizi yang tidak seimbang, istirahat yang kurang, pola makan yang tidak teratur, aktivitas pelajaran yang padat dilakukan setiap hari, kondisi lingkungan yang tidak sehat, kurang dalam menjalankan program latihan kesegaran jasmani.Melihat pada suatu keadaan tertentu terhadap kondisi tingkat VO2Max siswa yang mengikuti kegiatan ekstrakurikuler, maka pihak sekolah sebagai tempat berlangsungnya proses belajar mengajar, maka perlu perhatian intensif agar guru olahraga dapat memberikan bagi siswa yang mengikuti ekstrakurikuler gulat jika terdapat kategori tingkat VO2Max yang tergolong masih kurang.

Guru dapat melakukan inovasi dalam mengajar latihan gulat agar dapat disenangi oleh siswa yang ikut. Sehingga ketika datang latihan siswa dapat bersemangat dalam mengikutinya.Strategi yang dapat dilakukan seperti melalui metode permainan gulat yang menyenangkan sehingga dapat membuat siswa termotivasi untuk mengikuti gerakgerak yang dicontohkan oleh guru mereka.Ini akan berdampak pada siswa akan merasa ikut senang dan ikut aktif dalam pelajaran pendidikan olahraga. Selain itu juga, perlu dilakukan senam pagi sehingga siswa akan bersemangat dalam mengikuti pelajaran dikelas juga. Kebugaran jasmani sangat penting bagi setiap individu, agar segala aktivitas yang dilakukan dapat diselesaikan dengan baik.Latihan kebugaran jasmani dapat dilakukan secara rutin.

\section{KESIMPULAN DAN SARAN Simpulan}

Berdasarkan dari hasil penelitian maka diperoleh bahwa tingkat VO2Max siswa yang mengikuti kegiatan ekstrakulikuler gulat di SMA Negeri 1 Barusjahe Kabupaten Karo termasuk dalam kategori sedang sebanyak 9 orang siswa atau $60 \%$, pada kategori baik sebanyak 3 orang siswa atau $20 \%$ dan dikategori kurang sebanyak 3 orang siswa atau $20 \%$.Sehingga disimpulkan bahwa tingkat VO2Max pada siswa yang mengikuti kegiatan ekstrakulikuler gulat di SMA Negeri 1 Barusjahe Kabupaten Karo yaitu kategori sedang.

Saran

Adapun saran yang dapat diberikan pada penelitian ini adalah :

1. Perlu dilakukan peningkatan lagi bagi siswa yang masih kurang dalam kebugaran jasmani melalui latihan rutin

2. Untuk guru olahraga memperhatikan siswa ekstrakurikuler gulat yang masih memilki kurang tingkat VO2Max. Perlu melatih tata cara agar siswa tersebut dapat meningkatkan kebugaran jasmaninya.

3. Untuk peneliti selanjutnya agar menggunakan populasi yang lebih besar lagi dan membandingkan dengan sekolah lain yang memiliki ekstrakurikuler gulat. Selain itu juga jika memungkinkan agar dapat meneliti cabang olahraga lainnya yang mungkin ada diminati oleh siswa sebagai ekstrakurikuler di sekolah. Sehingga dapat diketahui berbagai masalah permasalah dan dapat ditemukan solusi untuk pemecahan masalah tersebut.

\section{DAFTAR PUSTAKA}

Arwin, A. (2017). Kontribusi Kekuatan Otot Lengan dan Kelincahan Terhadap Half Nelson Pada Atlet Gulat Provinsi Bengkulu. Kinestetik, 1(1).

Apri A. (2012). Olahraga Kebugaran jasmani sebagai suatu pengantar. Padang: Penerbit Sukabina Press

Bayu I. 2017. Profil Tingkat Vo2 Max Pada 
Siswa Sekolah Sepakbola (Ssb) Palembang Muda. Wahana Didaktika Vol. 15 No.3 September 2017 : 103112.

Benny, B. (2012). “Kontribusi Tingkat VO2 Max Terhadap Prestasi Atlet Unggulan Sulawesi Selatan". Competitor, Nomor 3 Tahun 4, Oktober: 12-22. Sulawesi selatan.

Budi BFS, Sugiharto. (2015). Circuit Training Dengan Rasio 1:1 Dan Rasio 1:2 Terhadap Peningkatan Vo2 Max. Journal of Sport Sciences and Fitness 4(3):53-58

Darsi, H. (2018).Pengaruh Senam Aerobic Low Impactterhadap Peningkatan V02max. Jurnal Gelanggang Olahraga 1 (2): 42-51. doi: 10.31539/jpjo.v1i2.134.

Hanafiah,S. (2015). Analisis Tingkat Vo2max Siswa Sma Negeri 1 Balung Kabupaten Jember. Jurnal Kesehatan Olahraga. 3(1): 276-286

Hastuti, T. A. (2008). Kontribusi Ekstrakurikuler Bolabasket Terhadap Pembibitan Atlet dan Peningkatan Kesegaran Jasmani. Jurnal Pendidikan Jasmanai Indonesia, 5(April), 45-50.

Kusuma,PA. (2015). Analisis Daya Tahan Aerobik Maksimal(Vo2max)Dan Anaerobikpada Atlet Bulutangkisusia 11-14 Tahunpb. Bintang Timursurabayamenjelang Kejurnas Jatim 2014. Jurnal Kesehatan Olahraga. 3(3):444-451.

Khomarul Ninzar. (2018). Tingkat Daya Tahan Aerobik (Vo2 Max) Pada Anggota Tim Futsal Siba Semarang. Jurnal Mitra Pendidikan. Vol. 2 No. 8 :738-749.

Intan Watulinga, Jornan J. V. Rampengan, Hedison Polii. 2013 "Pengaruh Latihan Fisik Aerobik Terhadap VO2 Max Pada Mahasiswa Pria Dengan Berat Badan Lebih (Overweight)".
Jurnal e-Biomedik (eBM),Volume.1/Nomer.2/Juli:10641068.

Pramitasari, Y. Indriana, and J. Ariati,. (2012). Hubungan Antara Persepsi Terhadap Metode Pembelajaran Kontekstual Dengan Motivasi Belajar Biologi Siswa Kelas Xi IPA SMAN 1 PANGKALAN KERINCI, RIAU. Jurnal Psikologi, vol. 9, no. 1, Mar. 2012. https://doi.org/10.14710/jpu.9.1.

Rahmad. (2016). Pengaruh Penerapan Daya Tahan Kardiovaskuler (Vo2max) Dalam Permainan Sepakbola Ps Bina Utama . Jurnal Curricula .1(1):1-10. doi: 10.22216/jcc.v2i2.1009.

Rismayanthi, C. (2012). Hubungan Status Gizi dan Tingkat Kebugaran Jasmani Terhadap Prestasi Hasil Belajar Mahasiswa. Jurnal Kependidikan: Penelitian Inovasi Pembelajaran, 42(1), 29-38. https://doi.org/10.21831/JK.V42I1.2 229

Suharjana. (2013). Kebugaran jasmani. Yogyakarta: Jogja Global Media.

Yuyun A. W. \& Fitria D. A. (2015). Pengembangan Ekstrakurikuler Sekolah. Yogyakarta: UNY Press.

Warni H, Arifin R, Bastian RA. (2017). Pengaruh Latihan Daya Tahan (Endurance) Terhadap Peningkatan Vo2max Pemain Sepakbola. Multilateral: Jurnal Pendidikan Jasmani dan Olahraga.16(2):121-126 